\title{
IMPLEMENTATION OF COMMUNITY BASED BREEDING PROGRAM TO IMPROVE GROWTH RATE AND MILK PRODUCTION PERFORMANCE OF ABERGELLE GOAT
}

\author{
Bewketu AMARE ${ }^{\star}$, Mulatu GOBEZE and Bekahgn WONDIM \\ Sekota Dry land Agricultural Research Center, P.O.Box 62 Sekota, Ethiopia \\ Email: bewketa21@gmail.com; (i) orciD: 0000-0002-5739-7438 \\ supporting Information
}

\begin{abstract}
The study aimed to identify farmers breeding objective and trait preference criteria, devising and implementing a pilot selective breeding scheme and establishing a model goat development scheme that can be applied under village conditions. A total of 1372 goats from 32 households were monitored for selection and data collection on growth performance, milk production, reproductive performance and other important characteristics. Best bucks were selected at yearly basis based on their indexed estimated breeding value and unselected bucks were culled from the population through castration and sale. Birth type, year of birth and parity had significant effect on pre-weaning growth performances. In this intervened pilot village with three round selections mean birth and yearling weight of kids had increased from $1.6 \pm 0.05 \mathrm{Kg}$ and $15.4 \pm 0.4 \mathrm{Kg}$ to $2.3 \pm 0.06 \mathrm{Kg}$ and $16.8 \pm 0.45 \mathrm{Kg}$, respectively. Total lactation milk yield was significantly affected by birth season and year while lactation length was affected by parity of doe's in addition to birth season and year. Average daily milk yield of doe's was $422.3 \pm 120.3 \mathrm{ml}$ and it was significantly differed between years. Higher body weight of the adult male (birth weight through yearling weight) with its color and strong feeding behavior were the most preferable traits, on the other hand milk production and good mothering ability were set for the doe's. In general, the breeding program was feasible, simple and compatible strategy to the smallholder farmers breeding practices as it avoids negative selection by allowing elite selected bucks for next generation. Genetic improvement in a single pilot-village will not bring an overall population improvement of the breed, and hence there is a need of scaling out of the breeding program to all the neighboring communities. Reproductive technologies (estrus synchronization with timed artificial insemination) need to be used. Since larger number of nine month to yearling male goats are leaving the village in one or other reasons, selection of bucks starting from nine months of age should be emphasized in the future. All doe's are not productive in terms of higher litter size and milk production at every stage of their reproductive age. So, keeping of very high parity dams will not provide profitable income to the households. Forage development strategies should be designed to improve data quality, increase production capacity of the breed and sustainability of the breeding program.
\end{abstract}

Key words: Abergelle goat, Birth weight, Selection, Traditional breeding system, Yearling weight

\section{INTRODUCTION}

Smallholder farmers in are obliged to search options to cope up under the existing conditions and pushed to livestock production in general, and small ruminant husbandry especially goats in particular, which become the major component of the farming system in the area (Yeheyis et al., 2012; Belay, 2013; Alubel, 2015). Abergelle goat, one of the most important goat breeds in Ethiopia have a population of 300,000 (Farm Africa, 1996) distributing in all agro-ecological zones of Waghimra contributes about $70 \%$ of liquid cash incomes of the household in lowland areas (FAO, 2019). This breed is characterized by its lower body weight, lower production potential, longer kidding interval and lower litter size with better meat quality and temperament in comparison to other indigenous goat breeds (Belay and Taye, 2013; Solomon, 2014; Alubel, 2015; Vorobyov et al., 2019). In addition, the growing demand of meat at the domestic as well as at the international markets increases the importance of goat in the national economy of the developing country (Solomon et al., 2014). Despite of the large population and multidirectional roles of goats in the area (Ethiopia), their productivity and contribution to the household as well as to the national economy is far below to its potential. Many of biological, environmental and socioeconomic constraints critically affected the sector. Among the constraints aforementioned here, biological factors especially poor genetic performance of indigenous breeds takes the lion share of overall lower productivity of livestock sector. Systematic breeding programs that can improve the genetic performance of indigenous breeds are not in place in our country. Little is known about the goat production system, breeding structure, genetic potential, breeding objective and their constraints and opportunities. Many small ruminant cross breeding activities in tropical countries are not effective due to incompatibility of genotypes to farmers breeding objectives, management method and prevailing environment of low input smallholding production system (Ayalew et al., 2003; Kosgey et al., 2006; Solomon, 2014). Thus, selective pure breeding of the adapted 
indigenous breeds is the best possible option of genetic improvement in the tropical countries (Marshall et al., 2019). Pure breeding applying community based breeding program is more appropriate breeding program for such a production systems (Solomon et al., 2009; Solomon et al., 2014). It is a new approach of genetic improvement program proposed for the low input traditional smallholder farming system as it considers the indigenous knowledge of the communities on breeding practices and breeding objectives (Aynalem et al., 2011; Wurzinger et al., 2011; Solomon, 2013; Solomon, 2014). A holistic community based selective breeding with growth only or very few traits considering the existing production system was a recommended approach for genetic improvement of Abergelle goat breed (Solomon et al., 2014). Therefore, the study was designed with the objectives of: defining farmers' goat selective breeding objectives, devising and implementing a pilot breeding scheme that can be applied under village conditions and finally establishing a model goat development village for technology testing, demonstration and promotion.

\section{MATERIALS AND METHODS}

\section{Description of the study area}

The study was conducted at Abergelle district, located at $12^{\circ} 56^{\prime} 02^{\prime \prime} \mathrm{N}$ and $38^{\circ} 57^{\prime} 22^{\prime \prime} \mathrm{E}$ which is 15 and $45 \mathrm{Km}$ far from the district Niruak and Sekota towns, respectively. The district has an area of 176,664.56 ha. Abergelle district has rugged topography characterized by mountains, steep escarpments and deeply incised valleys. The production system of Abergelle district is mixed crop-livestock system with high priority of Abergelle goat production. The traditional agro-ecological classification of the district comprises of Kola and dry-Woyna-Dega/dry-sub-moist highland with a respective share of 85 and 15 percent (Solomon, 2014). The rainfall of the district is very short with an erratic distribution. The mean annual average rainfall of the area was $250-750 \mathrm{~mm}$. with mean annual temperature of $23-37^{\circ} \mathrm{C}$. the main rainy season in the area starts from late June and to mid-July and ends during late August.

\section{Selection Criteria of the village}

The district was selected based on goat production potential, separate herding practice of their flock in the village, accessibility of roa and feed resources under irrigation and willingness of the farmers to participate in a community based goat improvement program. Initially, a total of 23 goat keepers were selected and had a continuous discussion on the principle and implication of community based goat improvement program. At the end of the discussions, 17 volunteer farmers were selected for final implementation of the activity and further baseline survey study. General household characteristics, purpose of keeping goats, livestock ownership, flock structure, trait selection criteria's of farmers, performance of goats, management and breeding practices and goat production constraints had been assessed. General information and farming systems of the study area were obtained from survey report by Solomon (2014) and Sekota Dry land Agricultural Research Center survey report as the district is one of the center's research mandate area. As well, reports of district office of agriculture and rural development were considered as secondary information during selection of the project village.

\section{Recording and flock management}

Two participating farmers from the project village were recruited and trained as an enumerator. Their roles were to coordinate the breeding program and collect pedigree and performance data from the participating village flocks. All animals in the villages were uniquely identified using plastic ear tags. In addition, local names were provided for each individual that helped us during the loss of an ear tag and to simplify the data recording processes. Data collection commenced prior to the start of the first round of selection. Baseline information collected includes parity of the doe's using farmer recall method, age of the doe's based on their dentition and farmers information, total flock number with each age class category of the households; and date of birth, dam identity, milk yield of the dam, birth weight and subsequent weights of kids sired by non-selected village bucks at the start of the breeding program. The performance of kids sired by unselected village sires served as a baseline or contrasts against which the genetic progress resulting from selection was assessed. After the selection activity started, data on mating, kidding and body weights were recorded. The enumerators made rounds of visits to the villages every morning to record kids born identify them by ear tags, milk data measurement and weigh the newborn. The kids were also weighed at three, six, nine and twelve months of age. Milk yield data were recorded up to twelve weeks at a week interval.

\section{Selection and mating}

A one-tier breeding structure was adopted; i.e. selection was implemented in the whole household goat population. All first birth kids of the population born from unselected previous village sires were evaluated and selected as first round breeding population, after all, the growth performance of individuals and milk production performance of their respective dams were recorded. Index selection method were implemented for the first two round selections (on yearling weight and dam ADMY traits) and for the recent two rounds selection through estimated breeding value of bucks were undertaken. All 10 to 12 month old bucks from all flocks in the project villages were evaluated together as cohorts. Selection of the best young buck was planned to be selected based on their yearling weight corrected for nongenetic factors (sex, birth type, season of birth, year of birth and parity of the dam) and to subject these criteria further to farmers' selection criteria which have been defined earlier (Solomon, 2014). Farmers, however, put heavier weights on their own subjective morpho-metrics type of criteria (i.e. color, body size and conformation) to select the bucks. The selected bucks were assigned to buck groups following an own flock mating plan due to larger flock sizes at each household by considering the previous mating history of bucks to avoid inbreeding (Solomon et al., 2009). Unselected bucks were culled through castration and sale as soon as the selection was done. In cases of small flock number faced during the selection process, group mating system was used. Bucks were rotated among the 
individual members based on mapped rotation modality by considering the grazing management of flocks, settlement and previous mating history. After completion of a single breeding season bucks were rotated to other farmers by considering the pre-set conditions and finally at the end of service period, they fattened at the cooperative for income generation.

\section{Data analysis}

Descriptive statistics were used to perform simple population characteristics. Own flock ranking and group ranking methods described by Solomon (2014) was used to identify the breeding objectives. Production and reproduction performance (quantitative) data were analyzed using the GLM procedures of SAS software. Birth type, sex, season of birth, parity and year were fitted as fixed factors for body weight variables whereas season of birth, parity and year were fitted for milk production traits. Least square mean with respective standard error was separated using Tukey-Kramer test. The following models for body weight and milk yield variables with the fixed effects were fitted.

\section{Yijkl $=\mu+B t i+S j+S b k+P I+Y m+e i j k l m$}

Where:

Yijlm = the observed growth performance of goat by weight mainly at six month to yearling weight

$\mu=$ overall mean

$\mathrm{Bti}=$ is the effect of ith birth type (Single and twin)

$\mathrm{Sj}=$ is the effect of $\mathrm{jth}$ sex (male and female)

$\mathrm{Sbk}=$ is the effect of kth birth season (wet and dry)

$\mathrm{PI}=$ is the effect of Ith parity (first to ninth)

$\mathrm{Ym}=$ is the effect of the mth year (2014-2017)

eijklm $=$ is random residual error
$\mathbf{Y i j k}=\boldsymbol{\mu}+\mathbf{S b i}+\mathbf{P j}+\mathbf{Y k}+\mathbf{e i j k}$

Where:

Yijkl = the observed milk yield

$\mu=$ overall mean

Sbi $=$ is the effect of ith birth season (wet and dry)

$\mathrm{Pj}=$ is the effect of jth parity (1-9))

$Y k=$ is the effect of kth season (2014-2017)

eijk $=$ is random residual error

\section{RESULTS AND DISCUSSION}

\section{Breeding objectives and trait selection criteria of farmers}

The primary objective of keeping goats in the study area was to use them as an immediate source of cash income and diverse livestock products that sustain the livelihoods of the community due to frequent crop production failure. The most preferred trait for doe's in the community were milk yield, good mothering ability and strong feeding behavior (drought resistance) in the existing extreme eroded and undulating areas. And for males, farmers had given more priority for color, body conformation and body size trait. The result is illustrated in Table 1.

\section{Population structure, flock size and off take rates}

The preliminary survey result of this study revealed that the flock size of goats per house hold (mean \pm SD) was $47.75 \pm 29$. Based on sex $27 \%$ of the populations are males and $73 \%$ are females. Reproductive doe's constitute the larger number (48\%) in the flock because of farmers demand on increased number of offspring's. The results of this study is slightly lower than the reports of Belay (2008) and Solomon (2014) who reported 56.6\% and 51.8\%, respectively. Lower number in this study was due to smaller number of household data used in comparison to them. Death, sale, share and slaughtering (Figure 1) were the major off take reasons in the monitored flock and the overall off take rate was higher at yearling weight and around. This is because during this stage more goats were brought to the market, consumed at household level during festivities and shared to herders. Population structure (mean \pm SD) with in each age class and percentage contribution is presented in Table 2.

\section{Milk Production}

Milk is the most important product consumed by all households. Milk production performance during the selection period presented in (Table 3 ) was significantly different $(p<0.0001)$ between years. It was significantly varied during each year in a decreasing fashion. The mean average daily milk yield ( $\pm \mathrm{SD}$ ) was $338.8 \pm 210 \mathrm{ml}$. Doe's that have given birth during wet seasons were produced higher amount of milk and longer lactation lengths because of the availability of feed was good in this season. The reasons for milk production decline in each year were related to; first, there was higher variability of lactation lengths in each year due to scarcity of feed and longer dry season that could not supported milk production in the recent two years. Second, flock mobility and dynamics were the most critical problems during the peak periods of lactations since farmers obliged to migrate their flocks to distant areas in search of feed for their animals in the long dry seasons and this resulted in improper implementation and data recording during these periods.

\section{Growth performance}

Growth performance was the most single important trait that farmers experienced to select their next parent stock conventionally. All growth traits (birth weight, weaning weight, six month weight, nine month weight and yearling weight) described in Table 3 and Table 4 was significantly affected by year during the course of selection period. The overall mean of weight at birth, three months, six months nine months and twelve months were $2.0 \pm 0.04 \mathrm{~kg}, 7.2 \pm 0.17 \mathrm{~kg}, 10.1 \pm 0.25$ $\mathrm{kg}, 13.0 \pm 0.24 \mathrm{~kg}$ and $15.9 \pm 0.4 \mathrm{~kg}$, respectively. Sex was not significantly affected by pre weaning and post weaning weights except at six months of age. Birth type had a significant effect up on the weaning ages and then after it was not affected. This could be due to the dependence of kids on their dams during their earlier ages and after their weaning the 
kids graze on the same grazing land and forages. Season of birth only had a significant effect at birth weight and it didn't affect all other growth performance traits. This is mainly because of the performance of grazing lands in the study area were similar that could not make the difference. Males, single born kids and those born during wet seasons had significantly higher birth weight than females, twin kids and dry season born ones, respectively. This could be due to higher physiological performance of males, under nourishment of the embryo in twins and the availability of forage during wet seasons that support increased follicular growth in does, respectively. In addition, the increase in weight at different age during the respective years of selection reflected the effectiveness of the breeding program that is implemented with a good management practices. The result of this study was higher than the reports of Belay and Taye (2013) which was $1.91,6.84,9.13$ and $14.25 \mathrm{Kg}$ for birth weight, weaning weight, six month weight and yearling weight, respectively. Growth performance traits were not significantly affected by parity of the doe but doe's with earlier and higher parity had a potential of giving lower litter. This could be due to underdeveloped state of the reproductive features in first parity dams compared with older doe's that have reached physiological maturity. It was in agreement with some other studies and the results of Belay and Taye (2013). Kidding interval, litter size and age at first kidding of the flock was almost the same with the results of Solomon (2014), 12.4 months, 1.04 and 15.5 months and lower than the reports of Belay (2008). Twining was only $3.4 \%$ in the intervened population of goats. This could be due to the fact that in this study growth performance records were involved in the selection process as it was a recommended breeding design for the breed and recording of multiple traits was not feasible in the community.

\begin{tabular}{llc} 
Table 1 - List of preferred traits by farmers (own flock ranking method for females and group animal \\
ranking for males), adopted from Solomon (2014). \\
\hline Sex $\quad$ Traits & Percentage (\%) \\
\hline & Milk Yield & 20.47 \\
& Drought resistance & 14.96 \\
& Body size & 14.17 \\
Female & Kid growth & 11.81 \\
& Twining & 10.24 \\
& Kidding Interval & 9.45 \\
& Other cumulative traits & 18.89 \\
\hline & Body size & 21.03 \\
& Color & 23.86 \\
Male & Body conformation & 10.12 \\
& Height & 9.09 \\
& Fast growth & 7.95
\end{tabular}

Table 2- Population structure, percentage contribution and off take amounts by different reasons at each households $(\mathrm{N}=764)$.

\begin{tabular}{lccc} 
Age group & Mean & SD & Percentage (\%) \\
\hline Male kid & 1.6 & 1.6 & 3.1 \\
Female kid & 0.6 & 1.8 & 1.2 \\
Weaned male & 12.1 & 4 & 13.1 \\
Weaned female & 22 & 9.1 & 23.8 \\
Doe & 44.2 & 13.6 & 48 \\
Buck & 7.4 & 3 & 8 \\
Castrated & 2.6 & 1.8 & 2.7 \\
\hline
\end{tabular}

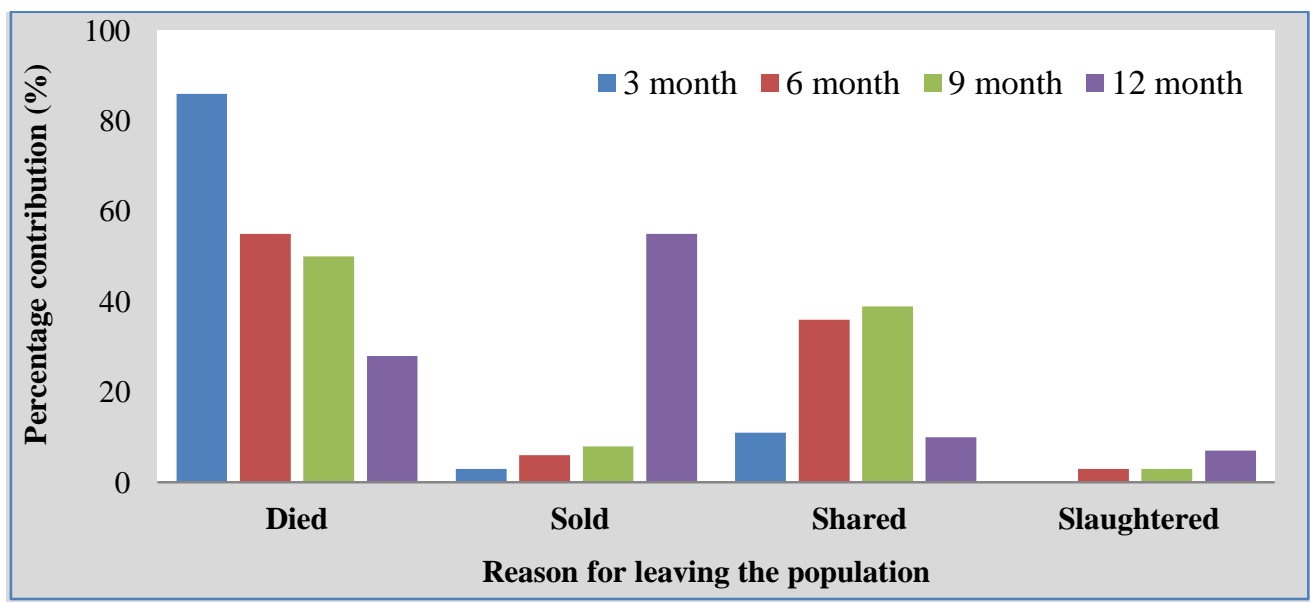

Figure 1 - Percentage of individuals leaving the population by different reason 
Table 3 - Least square means of daily milk yield and lactation length of goats under village condition

\begin{tabular}{|c|c|c|c|c|}
\hline \multirow{2}{*}{ Variables } & \multicolumn{2}{|c|}{ ADMY $(\mathrm{ml})$} & \multicolumn{2}{|c|}{ LL (weeks) } \\
\hline & $\mathbf{N}$ & LSM \pm SE & $\mathbf{N}$ & $\mathrm{LSM} \pm \mathrm{SE}$ \\
\hline Over all & 1033 & 338.8 & 1033 & 8.9 \\
\hline CV (\%) & - & 39.2 & - & 35.2 \\
\hline Season of birth (p) & - & 0.0001 & - & 0.0002 \\
\hline Dry & 423 & $226.4 \pm 13.8^{b}$ & 423 & $6.2 \pm 0.3^{b}$ \\
\hline Wet & 610 & $368.9 \pm 13.3^{a}$ & 610 & $8.7 \pm 0.3$ \\
\hline Year (p) & & 0.0001 & & 0.0002 \\
\hline 2006 & 366 & $440 \pm 14.4^{a}$ & 366 & $9.7 \pm 0.4^{a}$ \\
\hline 2007 & 324 & $409.6 \pm 14.1^{b}$ & 324 & $7.1 \pm 0.4^{b}$ \\
\hline 2008 & 344 & $375.1 \pm 13.4^{c}$ & 344 & $5.5 \pm 0.4$ \\
\hline Parity & - & 0.0002 & - & 0.0003 \\
\hline 1 & 159 & $224.3 \pm 13.5^{b}$ & 159 & $7.6 \pm 0.4^{b}$ \\
\hline 2 & 167 & $269.2 \pm 13.3^{a}$ & 167 & $8.4 \pm 0.4^{a}$ \\
\hline 3 & 166 & $281.5 \pm 13.5^{a}$ & 166 & $9.0 \pm 0.4^{a}$ \\
\hline 4 & 201 & $292.5 \pm 13.3^{a}$ & 201 & $8.8 \pm 0.3^{a}$ \\
\hline 5 & 145 & $257.3 \pm 13.3^{a}$ & 145 & $8.5 \pm 0.3^{a}$ \\
\hline 6 & 99 & $275.7 \pm 14.9^{a}$ & 99 & $7.7 \pm 0.4^{a}$ \\
\hline 7 & 48 & $280.7 \pm 18.1^{a}$ & 48 & $7.4 \pm 0.5^{b}$ \\
\hline 8 & 19 & $275.7 \pm 25.6^{a}$ & 19 & $7.6 \pm 0.8^{b}$ \\
\hline
\end{tabular}

Table 4 - Least square means ( \pm SE) of live body weights at different age (Kg) of Abergelle goats under village condition

\begin{tabular}{|c|c|c|c|c|c|c|c|c|c|c|}
\hline \multirow{2}{*}{ Variables } & \multicolumn{2}{|c|}{ BWT } & \multicolumn{2}{|c|}{ TMWT } & \multicolumn{2}{|c|}{ SMWT } & \multicolumn{2}{|c|}{ NMWT } & \multicolumn{2}{|r|}{ YWT } \\
\hline & $\mathbf{N}$ & LSM \pm SE & $\mathbf{N}$ & LSM \pm SE & $\mathbf{N}$ & LSM \pm SE & $\mathbf{N}$ & LSM \pm SE & $\mathbf{N}$ & LSM \pm SE \\
\hline Over all & 1372 & 2 & 942 & 7.2 & 836 & 10.09 & 632 & 13 & 371 & 15.9 \\
\hline CV\% & 26.5 & - & 20.4 & - & 21.13 & - & 12.8 & - & 15.6 & - \\
\hline $\operatorname{Sex}(p)$ & - & 0.06 & - & 0.06 & - & 0.04 & - & 0.07 & - & 0.07 \\
\hline Male & 707 & $2.02 \pm 0.04$ & 498 & $7.4 \pm 0.17$ & 452 & $10.1 \pm 0.25^{a}$ & 333 & $13.36 \pm 0.24$ & 181 & $16.6 \pm 0.4$ \\
\hline Female & 665 & $1.97 \pm 0.04$ & 444 & $7.3 \pm 0.17$ & 384 & $9.79 \pm 0.26^{b}$ & 299 & $13.14 \pm 0.25$ & 190 & $16.6 \pm 0.4$ \\
\hline Birth type (p) & & 0.0001 & & 0.001 & & 0.051 & & 0.06 & & 0.06 \\
\hline Single & 1271 & $2.07 \pm 0.04^{a}$ & 881 & $7.7 \pm 0.23^{a}$ & 783 & $9.95 \pm 0.34$ & 603 & $13.48 \pm 0.35$ & 360 & $17.00 \pm 0.77$ \\
\hline Twin & 51 & $1.93 \pm 0.06^{b}$ & 31 & $7.03 \pm 0.15^{b}$ & 27 & $9.92 \pm 0.22$ & 15 & $13.02 \pm 0.22$ & 11 & $16.13 \pm 0.24$ \\
\hline $\begin{array}{l}\text { Season of } \\
\text { birth }(p)\end{array}$ & - & 0.0001 & - & 0.06 & - & 0.06 & - & 0.062 & - & 0.064 \\
\hline Dry & 533 & $1.96 \pm 0.05^{b}$ & 407 & $7.4 \pm 0.17$ & 335 & $10.1 \pm 0.26$ & 223 & $13.38 \pm 0.26$ & 118 & $16.9 \pm 0.44$ \\
\hline Wet & 839 & $2.05 \pm 0.04^{a}$ & 535 & $7.34 \pm 0.17$ & 501 & $9.8 \pm 0.25$ & 409 & $13.12 \pm 0.24$ & 253 & $16.23 \pm 0.4$ \\
\hline Year (p) & - & 0.0001 & & 0.0001 & 0.0001 & 0.0001 & 0.0001 & 0.0001 & & 0.0001 \\
\hline 2014 & 395 & $1.7 \pm 0.05^{d}$ & 319 & $7.01 \pm 0.18^{b}$ & 263 & $9.34 \pm 0.27^{b}$ & 220 & $12.76 \pm 0.26^{b}$ & 156 & $15.4 \pm 0.4^{b}$ \\
\hline 2015 & 393 & $1.9 \pm 0.05^{c}$ & 294 & $.07 \pm 0.18^{b}$ & 278 & $9.21 \pm 0.26^{b}$ & 214 & $13.06 \pm 0.25^{b}$ & 92 & $17.48 \pm 0.45^{a}$ \\
\hline 2016 & 373 & $2.1 \pm 0.05^{b}$ & 329 & $8.02 \pm 0.17^{a}$ & 295 & $11.26 \pm 0.26^{a}$ & 198 & $13.94 \pm 0.26^{a}$ & 123 & $16.8 \pm 0.45^{a b}$ \\
\hline 2017 & 210 & $2.4 \pm 0.06^{a}$ & - & - & - & - & - & - & - & - \\
\hline Parity (p) & - & 0.05 & - & 0.052 & - & 0.06 & - & 0.06 & 0.06 & 0.06 \\
\hline 1 & 217 & $1.87 \pm 0.05$ & 147 & $7.11 \pm 0.16$ & 127 & $9.87 \pm 0.24$ & 93 & $13.3 \pm 0.24$ & 64 & $16.8 \pm 0.52$ \\
\hline 2 & 215 & $1.95 \pm 0.05$ & 154 & $7.68 \pm 0.15$ & 138 & $10.23 \pm 0.23$ & 99 & $13.35 \pm 0.24$ & 56 & $16.3 \pm 0.53$ \\
\hline 3 & 204 & $2.06 \pm 0.05$ & 150 & $7.54 \pm 0.15$ & 130 & $9.85 \pm 0.24$ & 112 & $13.23 \pm 0.23$ & 73 & $16.34 \pm 0.51$ \\
\hline 4 & 226 & $2.03 \pm 0.05$ & 179 & $7.59 \pm 0.14$ & 160 & $10.1 \pm 0.22$ & 124 & 13.320 .22 & 82 & $16.78 \pm 0.5$ \\
\hline 5 & 193 & $1.99 \pm 0.04$ & 143 & $7.67 \pm 0.15$ & 127 & $10.28 \pm 0.23$ & 96 & $13.42 \pm 0.23$ & 49 & $16.52 \pm 0.5$ \\
\hline 6 & 133 & $2.04 \pm 0.05$ & 86 & $7.71 \pm 0.17$ & 81 & $10.7 \pm 0.26$ & 52 & $13.32 \pm 0.27$ & 31 & $17.21 \pm 0.57$ \\
\hline 7 & 75 & $2.06 \pm 0.06$ & 40 & $7.01 \pm 0.24$ & 32 & $9.95 \pm 0.4$ & 24 & $12.5 \pm 0.35$ & 11 & $16.74 \pm 0.8$ \\
\hline 8 & 34 & $2.05 \pm 0.09$ & 17 & $7.29 \pm 0.36$ & 15 & $9.81 \pm 0.56$ & 10 & $13.02 \pm 0.53$ & 4 & $15.8 \pm 1.25$ \\
\hline
\end{tabular}

BWT=birth weight, TMWT=three month weight, SMWT=six month weight, NMWT=nine month weight, YWT= yearling weight, $N=$ total population, LSM= least square means and SE= standard error,

\section{CONCLUSION AND RECOMMENDATIONS}

Community based breeding program is compatible and simple strategy that goes in line with farmers breeding practice as it can avoid negative selection due to the elite sires were able to stay and mate at the breeding population. Higher body weight of the adult male (birth weight through yearling weight) with its color and strong feeding behavior were the most preferable traits, on the other hand milk production and good mothering ability were set for the doe's. Mean birth weight of kids has increased from $1.7 \mathrm{Kg}$ to $2.4 \mathrm{Kg}$ in the intervened pilot village. Off take rates were high during nine month to yearling periods that the farmers either sale the animals or share them to the herder to cover their wider demand. Based on the above strong justification the following recommendations are forwarded. 
- Genetic improvement in a single pilot-village will not bring an overall population improvement of the breed, and hence there is a need of scaling out of the breeding program to all the neighboring communities.

- Selection of sire before nine month should be recommended in order to reduce negative selection.

- Reproductive technologies (estrus synchronization with timed artificial insemination) need to be used in the community based villages to provide wider improved genotypes within a single breeding season.

- All doe's are not productive in terms of higher litter size and milk production at every stage of their reproductive age. So, keeping of very high parity dams will not provide profitable income to the households.

- Since larger number of nine month to yearling male goats are leaving the village in one or other reasons, selection of bucks starting from nine months of age should be emphasized in the future.

- Forage development strategies should be designed to improve data quality, improve production capacity of the breed and sustainability of the breeding program.

\section{DECLARATIONS}

The authors declare that we have not conflict of interest. Bewketu Amare, Mulat Gobeze and Bekahagn Wondem have declared and agree the rule of the journal and put the signatures on the declaration form. We all are first Authors/corresponding Authors of the papers. The contributions of the Authors are from initiation of the paper until final write up.

\section{Acknowledgment}

The Authors would like to thank Sekota dry land agricultural research center, Ethiopia for their support

\section{REFERENCES}

Alubel A (2015). On-farm phenotypic characterization and performance evaluation of Abergelle and Central highland goat breeds as an input for designing community-based breeding program. MSc thesis, Haramya University, Ethiopia. Google Scholar I Link

Ayalew W, Rischkowsky B, King JM and Bruns E (2003). Crossbreds did not create more net benefits than indigenous goats in Ethiopian smallholdings. Agriculture System, 76:1137- 1156. DOI: https://doi.org/10.1016/S0308-521X(02)00033-1

Aynalem H, Wurzinger M, Mueller J, Mirkena T, Duguma G, Mwai O, Sölkner J, Rischkowsky B (2011). Guidelines for Setting up Community-based Sheep Breeding Programs in Ethiopia. ICARDA Tools and Guidelines 1. International Center for Agricultural Research in the Dry Areas. pp. 37. ISBN 92-9127-255-8. DOI: https://doi.org/10.1017/S207863361300043X

Belay D (2008). Growth, Reproductive Performance and Carcass Characteristics of Abergelle and Central Highland Goat types under Traditional and Slightly Improved Management in Sekota Woreda. MSc thesis, Haramaya University. pp. 89. Google Scholar

Belay D and Taye M (2013). Evaluation of growth performance of Abergelle Goats under Traditional management systems in Sekota district, Ethiopia. Pakistan Journal of Biological Sciences, 16(14): 692-696. DOI: http://dx.doi.org/10.3923/pjbs.2013.692.696

FAO (2019). Livestock, health, livelihoods and the environment in Ethiopia, An integrated analysis. Food and Agriculture Organization of the United Nations, Rome, 2019. Link: http://www.fao.org/3/ca3621en/ca3621en.pdf

Farm Africa (1996). Goat types of Ethiopia and Eritrea. Physical description and management systems. Published jointly by FARM-Africa, London, UK, and ILRI (International Livestock Research Institute), Nairobi, Kenya. Google Scholar I Link

Kosgey IS, Baker RL, Udo HMJ and van Arendonk JAM (2006). Successes and failures of small ruminant breeding programs in the tropics: a review. Small Ruminant Research, 61: 13-28. DOI: https://doi.org/10.1016/j.smallrumres.2005.01.003

Marshall K, Gibson JP, Mwai O, Mwacharo JM, Haile A, Getachew T, Mrode R and Kemp SJ (2019). Livestock genomics for developing countries African examples in practice. Frontiers in Genetics, 10: 297. DOI: https://doi.org/10.3389/fgene.2019.00297

Solomon A (2014). Design of community based breeding programs for two indigenous goat breeds of Ethiopia. Doctoral Thesis. Vienna, Austria. Google Scholar I Link

Solomon A, Sölkner J, Solomon G, Tadele D, Aynalem H, Tadele M and Wurzinger M (2014). Optimizing alternative schemes of community-based breeding programs for two Ethiopian goat breeds. Acta Agraria Kaposváriensis, 18: 47-55. Google Scholar I Link

Solomon G, Komen H and Van Arendonk JAM (2009). Optimal village breeding schemes under smallholder sheep farming systems. Livestock Sciences, 124: 82-88. Google Scholar I DOI: https://doi.org/10.1016/j.livsci.2009.01.001

Solomon G, Tesfaye G, Edea Z, Tadele M, Duguma G, Tibbo M, Rischkowsky B, Mwai O, Tadele D, Wurzinger M, Solkner J. and Haile A (2013). Characterization of indigenous breeding strategies of the sheep farming communities of Ethiopia: A basis for designing community-based breeding programs. ICARDA working paper, Aleppo, Syria. No. 565-2016-38938. pp. 47. Google Scholar I Link

Vorobyov V, Vorobyov D, Polkovnichenko P and Safonov V (2019). Evaluation of hematological and metabolic parameters in small ruminants with trace elements deficiency under different biogeochemical conditions. World's Veterinary Journal, 9(4): 311-316. Link

Wurzinger M, Sölkner J and Iniguez L (2011). Important aspects and limitations in considering community-based breeding programs for low-input smallholder livestock systems. Small Ruminant Research, 98: 170-175. Google Scholar I Doi: https://doi.org/10.1016/j.smallrumres.2011.03.035

Yiheyis A, Tegegn F, Melekot MH and Taye M (2012). Pre-Weaning Growth Performance of Sekota Sheep Breed in Waghimra Zone , Ethiopia. Online Journal of Animal and Feed Research, 2(4): 340-343. Google Scholar I Link 